\title{
Set in stone? A perspective on the concrete sustainability challenge
}

\section{Krystyn Van Vliet, Roland Pellenq, Markus J. Buehler, Jeffrey C. Grossman, Hamlin Jennings, Franz-Josef UIm, and Sidney Yip}

\begin{abstract}
As the most abundant engineered material on Earth, concrete is essential to the physical infrastructure of all modern societies. There are no known materials that can replace concrete in terms of cost and availability. There are, however, environmental concerns, including the significant $\mathrm{CO}_{2}$ emissions associated with cement production, which create new incentives for university-industry collaboration to address concrete sustainability. Herein, we examine one aspect of this challenge-the translation of scientific understanding at the microscale into industrial innovation at the macroscale-by seeking improvements in cement-paste processing, performance, and sustainability through control of the mechanisms that govern microstructure development. Specifically, we consider modeling, simulation, and experimental advances in fracture, dissolution, precipitation, and hydration of cement paste precursors, as well as properties of the hardened cement paste within concrete. The aim of such studies is to optimize the chemical reactivity, mechanical performance, and other physical properties of cement paste to enable more sustainable processing routes for this ubiquitous material.
\end{abstract}

\section{Sustainability challenges and opportunities}

With more than one-half of the world's growing population (now $\sim 7$ billion) living in cities, a sustainable physical infrastructure is central to improving and maintaining a high quality of life. Concrete is an important component of this infrastructure, with a current annual per capita consumption of about 2.8 tonnes $(t)$ (Figure 1). Concrete powers a worldwide US $\$ 35$ billion industry, employing more than two million workers in the United States alone. This high demand is driven by a number of remarkable properties of this material (Table I), with which a structural composite with complex geometry and high strength can be created on demand by mixing water with cement powder and stone. This "liquid stone" processing capacity enables rapid construction and repair of geometrically complex pavements, bridges, buildings, and waterways. However, such high usage carries a price associated with Earth's finite resources and limited tolerance for industrial byproducts. Sustainable use of concrete requires that its function and costs (in economic, environmental, energy, and social terms) be evaluated within the context of its end use and that new and highly optimized materials be developed (Table I). Life-cycle assessment shows quantitatively that the greatest environmental burden from structures such as buildings occurs during the use stage, ${ }^{5}$ which presents new priorities for the exploration of property and processing optimization.

As illustrated in Figure 2, concrete is manufactured locally and directly from readily available limestone and clay, which are mixed without refinement and then heated in a large, rotating kiln (up to $200 \mathrm{~m}$ in length) to temperatures of about $1500^{\circ} \mathrm{C}$. Carbon dioxide is generated from both the combustion to provide heat and the decomposition of limestone $\left(\mathrm{CaCO}_{3}\right)$. A large kiln can produce up to $10,000 \mathrm{t}$ of so-called clinker nodules per day, which are then ground into a fine gray powder, with addition of gypsum. The resulting so-called portland cement is transformed into familiar concrete by the addition of sand and gravel and, most importantly, water. Whereas sand and gravel are largely inert fillers, a chemical transformation occurs that turns the cement-water mixture from a liquid suspension into a solid binding matrix called cement paste. One indication of the 


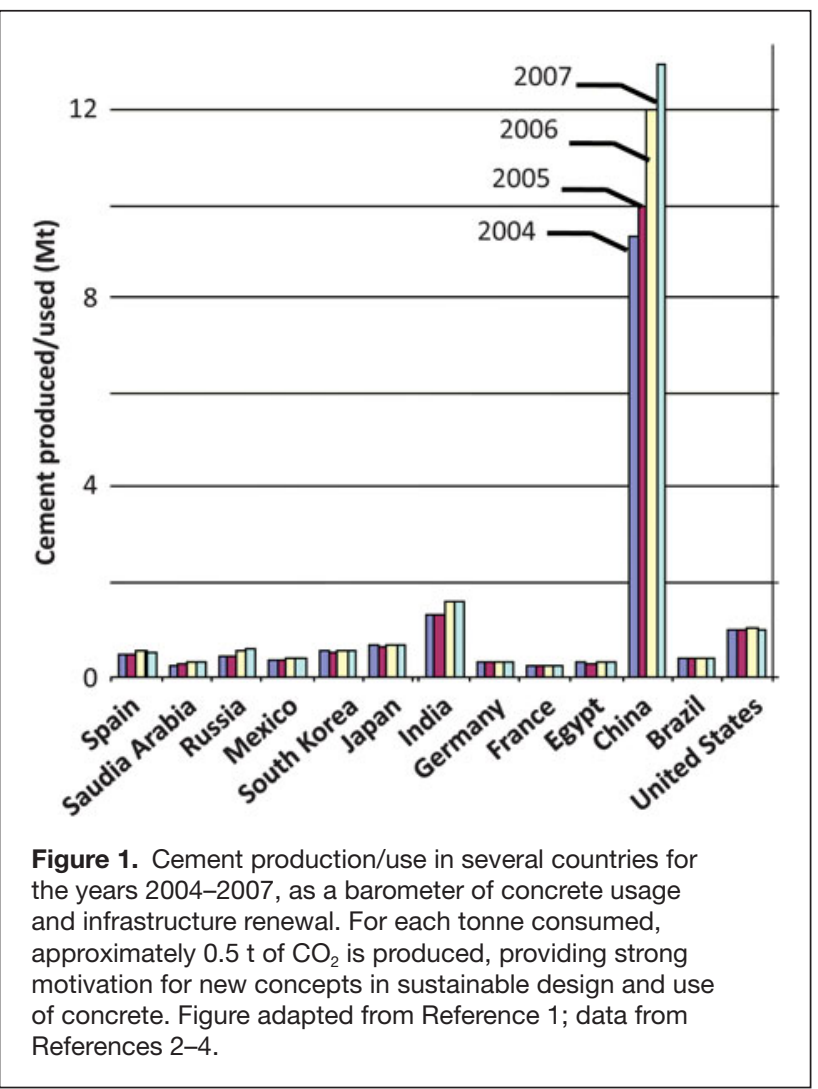

complexity of the reaction is the long induction period, lasting for several hours after mixing, giving time for transport and placement. This is followed by relatively rapid hardening into a load-bearing solid.

For decades, it has been broadly accepted that the scale of relevance for several properties of cement-based materials is the atomic scale, although realization of the structure and properties at this scale has been achieved only recently. This

\begin{tabular}{|l|c|c|}
\hline \multicolumn{2}{|c|}{ Table I. Properties of cement or cement paste (not concrete), with associated goals that will assist } \\
in reducing the environmental footprint.
\end{tabular}

a Data acquired from broad literature and Portland Cement Association. article discusses the opportunities and challenges inherent in predicting key synthesis and property benchmarks of cement paste, with a specific focus on connecting atomistic simulations to performance. Ultimately, the goal is to identify opportunities for improving the sustainability of our built infrastructure. Such potential can be illustrated by considering how changes in the composition of precursor materials affect energy consumption; how simulations can predict rates of setting, which, in turn, affect construction speed and thus pollution; and how the improved physical and mechanical properties of cement paste can reduce materials and energy consumption in new infrastructural designs.

We first outline the key steps in cement and concrete production, to illustrate opportunities for innovation at the microscale to lead to improvements at the macroscale. Next, we discuss specific examples wherein computational modeling and simulation have been related to experiments in a way that both offers new routes of inquiry and exposes the current challenges in relating molecular mechanisms to practical performance and sustainability.

\section{Innovation in cement and concrete science}

Traditionally, advances in cement and concrete performance have been made through iterative experiments focused on macroscale behavior in physical structures that have lifetimes of several decades. Such approaches can be regarded as "top-down" in that the engineering of the mechanical properties of the system is governed by the design goals at the macroscale. In contrast, the "bottomup" approach to materials design starts at a smaller scale, where the material is described as an assembly of atoms and molecules arranged in a certain structure, and works up through the mesoscale to the macroscale to achieve improved functionality. In this article, we discuss the latter approach in the context of cement-science innovation, with attention to the challenges and opportunities of bridging the microscale-macroscale gap to address challenges in environmental sustainability and enable new applications.

To relate the basic steps of concrete production to fundamental material processes and sustainability, consider the simplified schematic in Figure 2. The final product for infrastructure is typically concrete, obtained by adding aggregate (e.g., gravel, stone) at the mixing stage. The cohesion within concrete is attributed to the hardened paste, also called the binder phase. It is a noncrystalline compound of calcium silicate hydrate, $\mathrm{CaO}-\mathrm{SiO}_{2}-\mathrm{H}_{2} \mathrm{O}$ (C-S-H), where the hyphens indicate a variable, nonstoichiometric composition. From the standpoint of materials science innovation, there exist 

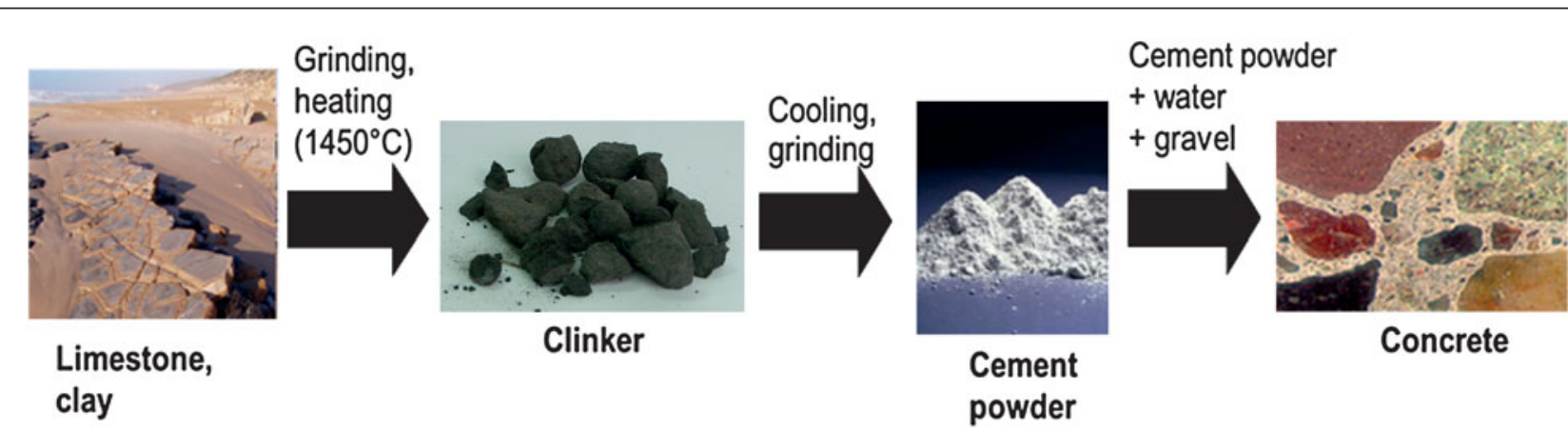

Concrete

Figure 2. Cement processing, including heating and grinding of limestone and clay to produce clinker, cooling and grinding of clinker to produce cement powder, mixing of the powder with water (hydration) to initiate setting, and evolution of the hardened paste. Gravel is added at the mixing stage to produce concrete. The images of cement powder and concrete were obtained from the Portland Cement Association and CSM Instruments, respectively, and were used with permission.

several opportunities for fundamental studies that can impact concrete sustainability. We illustrate this by (1) considering the clinker grinding process from a fracture-mechanics perspective, (2) modeling clinker dissolution through electronic-structure calculations, (3) studying C-S-H precipitation and cement paste setting through atomistic simulations, and (4) probing the structural and mechanical behavior of the hardened paste.

In materials research, it has been recognized that a multiphysics (or multidisciplinary), multiscale approach can be useful in correlating complex microstructures with macroscopic physical properties. Given the structural, chemical, and mechanical phenomena indicated in Figure 2 and the emerging tools of both modeling and simulation ${ }^{6,7}$ and characterization, ${ }^{7}$ one can identify a number of materials phenomena for the study of mechanisms at the microscale. A selection of the processes relevant to concrete processing (in Figure 2) is shown in Figure 3. What is envisaged is a progression (from left to right) in capability to perform modeling studies at increasingly larger scales. In the microscale domain, individual phenomena such as clinker grinding, clinker dissolution, C-S-H precipitation, and setting can be investigated as standalone problems. This type of research is feasible through materials modeling and simulation. The results of such studies can then be passed to mesoscale simulations, performed using cement hydration codes that are currently being developed. ${ }^{8,9}$ The expectation is that these simulations will give hydration characteristics (heat curves and set times) that also can be obtained in macroscale industrial laboratory tests on specimens of the actual cement paste and concrete that will be poured at a construction site. It is the linking of the micro- to the macroscale - from computational predictions to experiments - that will enable atomic-scale innovations to impact performance relevant to industry and users. This, then, is the goal of mechanism-based concrete sustainability research. It is clear that bridging this gap - from microscale to macroscale and from fundamental research to industrial implementation - is an endeavor critical to the advancement of sustainable concrete, as well as a challenge shared with nearly all materials-enabled applications.

\section{Stages of cement-paste development Clinker grinding and dissolution}

Today's cement is essentially created from a synthetic rock, called clinker, which is a heterogeneous material. ${ }^{10}$ Alite and belite, the two major clinker phases, are solid solutions of calcium silicates, $\mathrm{Ca}_{3} \mathrm{SiO}_{5}$ (denoted $\mathrm{C}_{3} \mathrm{~S}$ ) and $\mathrm{Ca}_{2} \mathrm{SiO}_{4}$ (denoted $\mathrm{C}_{2} \mathrm{~S}$ ), respectively, typically stabilized by a few percent of impurities. (Aluminates and ferrites are the other phases

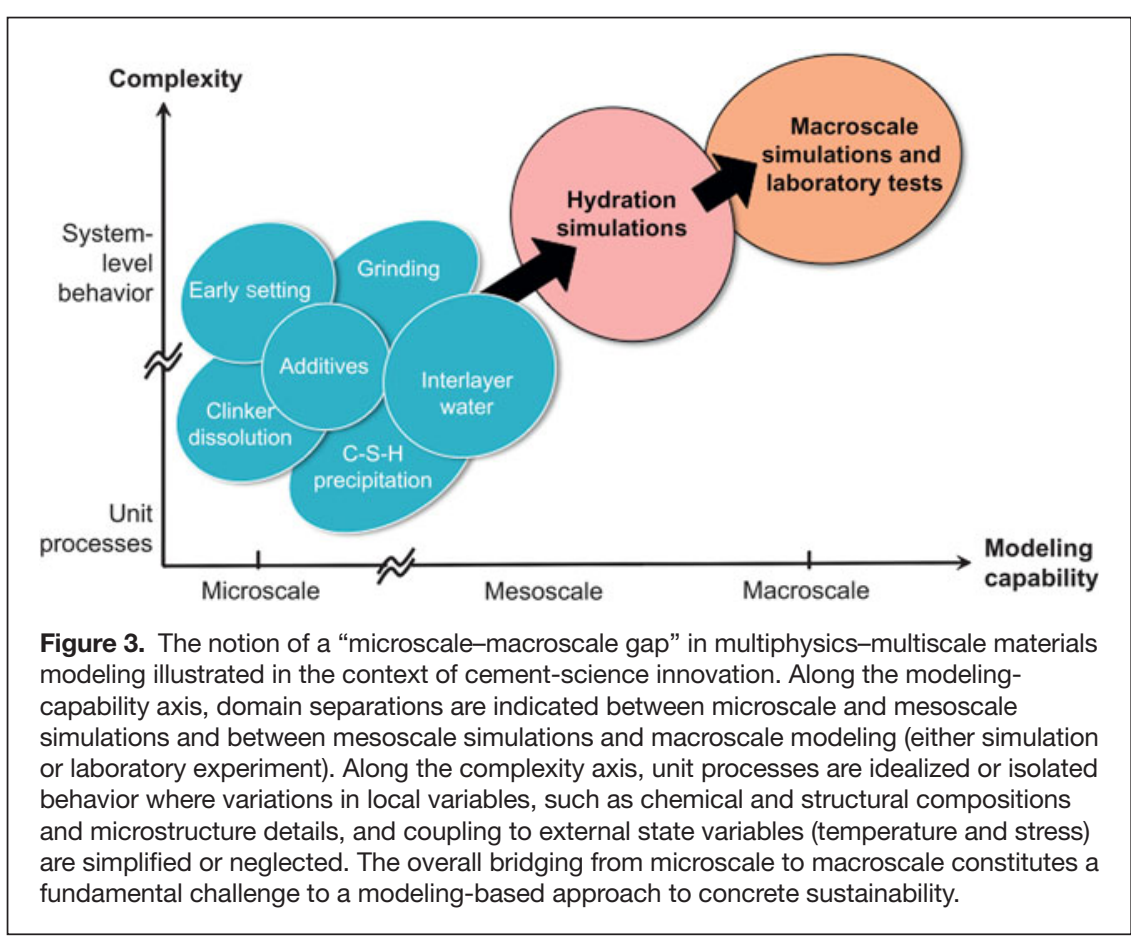


commonly present in industrial clinker.) For all cement clinker compositions, the last manufacturing step includes mechanical grinding. The energy required to grind these nodules into powder can be related to the fundamental fracture properties of clinker, which can be accessed by experiment and simulation. Ulm et al. developed a scratch-based experimental approach to estimate a mixed-mode fracture toughness, $K_{\mathrm{c}}$, from lateral scratch-force-versus-distance measurements (Figure 4a,b) and showed that the $K_{\mathrm{c}}$ value of belite is 2-3 times that of alite, ${ }^{11}$ implying that the grinding energy is 4-9 times greater for belite. This quantification of the microscale fracture toughness of belite (and thus greater mechanical energy and associated $\mathrm{CO}_{2}$ production to fracture it) presents an interesting environmental tradeoff, in that increased use of belite clinker would reduce the associated $\mathrm{CO}_{2}$ burden of the clinker because belite contains less calcium oxide than does alite.

Indeed, researchers have long pursued a modification to the manufacturing process that would allow for a decrease in cement's environmental footprint through the use of belite as the main clinker phase. This motivation is due in part to the lower $\mathrm{CaO}$ composition and in part to the lower temperature necessary to produce belite $\left(\sim 1200^{\circ} \mathrm{C}\right.$, or $\sim 300^{\circ} \mathrm{C}$ less than that required for alite). ${ }^{9}$ Clearly, the reduction in energy required to form belite would provide both economic and environmental benefits. ${ }^{12}$ However, the lower reactivity of belite with water prevents belite-rich cement from fulfilling the required strength development standards (i.e., sufficiently short reaction times and setting/curing times) under time constraints of construction, ${ }^{13}$ which dramatically reduces its use. Thus, the more reactive alite phases dominate (typically $70-80 \%$ ) in new infrastructure.

An atomic understanding of clinker solubility has not yet been achieved, with intriguing hypotheses awaiting validation. ${ }^{14}$ In fact, despite the vast recent literature on cement hydrates, ${ }^{11,15-19}$ previous studies on clinker are rather scarce ${ }^{20,21}$ and mainly focused on structural properties, ${ }^{22}$ with a few experimental results suggesting possible influences on reactivity. ${ }^{23,24}$ These limited data show discrepancies and leave many unanswered questions, and thus, the search for a belite phase with higher reactivity has been carried out chiefly by trial and error. Several strategies have been attempted, including modifying the chemical structure of belite by thermal processing or by including chemical impurities. ${ }^{25-28}$ Despite partial success, ${ }^{28}$ there is little control or understanding of where atomic substitutions take place, their effect on structure, or their role in chemical reactions. For these reasons, a more detailed, accurate, and clear understanding is needed to suggest new paths for improving the reactivity of cement components producing lower amounts of $\mathrm{CO}_{2}$.

Figure $4 \mathrm{c}$ illustrates one possible path forward in understanding the impurity-altered reactivity of clinker, using electronicstructure-based calculations of pure and chemically substituted belite to design "quantum clinker." The crystallographic faceting (as determined using the well-known Wulff construction) and dissolution reactions with water can be understood and manipulated from first-principles calculations for $\mathrm{C}_{2} \mathrm{~S}$ as a function of impurities. ${ }^{29}$ The charge densities of both the conduction-band maximum (CBM) and the valence-band maximum (VBM) are considered upon the introduction of magnesium, aluminum, and iron impurities into $\mathrm{C}_{2} \mathrm{~S}$ at concentrations of $0.5 \%, 1 \%$, and $2 \%$. Compared with pure $\mathrm{C}_{2} \mathrm{~S}$, the delocalized conduction band is altered upon magnesium and aluminum substitution, accumulating on the oxygen atoms and around the impurities. This localization effect is stronger for aluminum, resulting in a more reactive region around the impurity that is susceptible to nucleophilic attack, for example, upon exposure to water during dissolution. The VBM is still primarily located at the oxygen atoms upon magnesium and aluminum substitution, although it is more localized on those oxygen atoms that are nearest the impurities. One can hypothesize that this change might increase the reactivity of silicate groups near the impurity, at the cost of decreasing the number of sites that can interact with electrophilic cations; such predictions can be tested experimentally. This perspective on the role of impurities 
will be needed to design new clinker materials with enhanced dissolution properties. Further, the correlation of fracture resistance upon grinding with chemical reactivity upon dissolutionthrough both experiment and modeling at larger length scaleswill help to elucidate the relative effects of faceted surface energy and reaction kinetics of clinker. These nanoscale effects facilitate C-S-H precipitation and cement-paste setting at longer time and length scales.

\section{C-S-H precipitation and early setting}

The hardening of cement paste, once the powder is mixed with water, is what gives concrete its wide utility. ${ }^{30}$ Despite its importance, several recent reviews make clear that the processes that occur at the microstructure level and various stages of hydration are not yet well understood. , $, 8,31,32$ Figure 5a shows how the complex shear modulus of a cement paste, measured by ultrasonic wave propagation, increases during two distinct intervals, separated by a period of apparent inactivity. ${ }^{33}$ This is the characteristic behavior of cement setting, the mechanical response of the paste undergoing cement hydration. Although the overall increase in stiffness is universally accepted, detailed analysis of such data is currently not feasible because the microstructure evolution of the paste has not been characterized. To contrast this behavior with the kinetics of setting, Figure $5 \mathrm{~b}$ shows a typical heat-release curve commonly considered in discussions of cement hydration. ${ }^{30}$ Five stages of temporal evolution are distinguished: initial deceleration, incubation, strong acceleration, second deceleration, and slow decay.

Attempts have been made to interpret various parts of the hydration curve. ${ }^{8,30,31}$ For example, the first deceleration

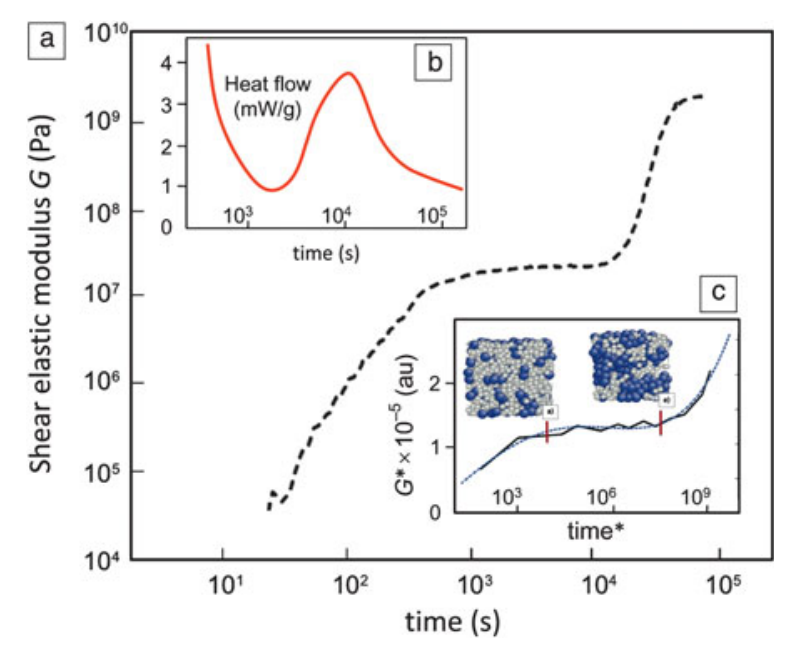

Figure 5. Time responses of a freshly made cement paste. (a) Increase of the shear elastic modulus measured by ultrasonic propagation in a paste with a water-to-cement ratio of 0.8; data from Reference 33. (b) Schematic of a hydration curve measured by calorimetry. (c) Shear modulus of a binary colloidal model simulated using a combination of molecular dynamics and metadynamics, as described in the text. ${ }^{38,39}$ is associated with the precipitation of hydration products, principally C-S-H but also " $\mathrm{CH}$ " [portlandite, $\left.\mathrm{Ca}(\mathrm{OH})_{2}\right]$. The incubation period and the onset of a strong acceleration are generally attributed to delayed nucleation of hydrates prior to an autocatalytic growth of the hydration products. The second deceleration signals the growth (precipitation) of the hydration products into open spaces (pores), whereas the slow decay indicates densification in the paste. Beyond such qualitative interpretations, quantitative description of any portion of the hydration curve remains a subject of future research. In the same context, a systematic study of the correspondence and differences between measurements of setting and hydration is also in order.

Current efforts in modeling and simulation of cement hydration kinetics and associated microstructure evolution have focused primarily on development of mesoscale codes that can account for particular measurements. ${ }^{8}$ Emphasis has been placed on hydration morphology, ${ }^{34}$ coupled diffusion and reaction, ${ }^{35}$ cellular-automata descriptions of reaction and transport, ${ }^{36}$ and a rule-based simulation platform allowing for input distributions of hydration products and particle sizes. ${ }^{9}$ Collectively, these codes represent mesoscale simulation capabilities that can potentially incorporate input from microscale modeling and simulation studies (such as clinker dissolution rates) to predict hydration behavior measurable in a laboratory (of the entire paste volume). This is the role envisaged for hydration simulation capabilities in Figure 3, where links to laboratory tests will be a critical step in bridging the "microscalemacroscale" gap.

A specific example of microstructure development in cement setting that needs better understanding is the heterogeneous precipitation (nucleation and growth) of C-S-H and other hydration products that gives rise to the second increase in stiffness in Figure 5a. It is possible that atomistic simulations could help elucidate hydration mechanisms at the molecular level, but this is not as straightforward as it might first appear. Standard molecular-dynamics simulations will have difficulties accessing the relevant time scales indicated in Figure 5, as such simulations are capable of resolving time scales on the order of nano- or microseconds. Simulation techniques that accelerate the sampling of rare events by using history-dependent bias potentials (metadynamics) are being developed. ${ }^{37,38}$ One such algorithm has been applied to the kinetics of microstructure evolution of a binary colloidal mixture (with angle-dependent interactions) as a conceptual model for cement setting. ${ }^{39,40}$ The time variation of the shear modulus simulated by this model is displayed in Figure 5c, showing a qualitative correspondence with the experimental setting curve. On the basis of this model, one would interpret the initial modulus increase as arising from gelation of the solvent particle (species A), the induction period as diffusion of the solute particles (species B) to form clusters, and setting as the percolation of clusters of $\mathrm{B}$. Work is ongoing to introduce the precipitation and packing of C-S-H particles more explicitly to test the hypothesis that hardening of the paste can be described as heterogeneous densification. ${ }^{40}$ 


\section{Properties of the hardened paste}

The hardened paste, mainly the C-S-H phase, can be considered as a continuous porous matrix with multiple characteristic length scales ranging from nanometers to millimeters (based on smallangle $\mathrm{x}$-ray or neutron scattering data $^{41}$ ) or as a granular material (based on nanoindentation measurements ${ }^{42}$ ). The dimensions and structure of the C-S-H unit (i.e., of the C-S-H grain in a granular interpretation) are matters of active experimental and computational study, with reported dimensions ranging from a few nanometers ${ }^{15}$ to a few tenths of a nanometer. ${ }^{43} \mathrm{As} \mathrm{C}-\mathrm{S}-\mathrm{H}$ is a nonstoichiometric compound, composition is measured in terms of the $\mathrm{Ca} / \mathrm{Si}$ ratio (often denoted as $\mathrm{C} / \mathrm{S}$ ), which ranges from 1.2 to $2.2,{ }^{44}$ with maximum probability at $\mathrm{C} / \mathrm{S}=1.7$. The precise in situ measurement of the density of this common material $(2.6 \mathrm{~g} /$ $\mathrm{cm}^{3}$ ) was reported only recently. ${ }^{15} \mathrm{At}$ the nanoscale, diffraction and transmission electron microscopy (TEM) indicate that the $\mathrm{C}-\mathrm{S}-\mathrm{H}$ phase is semicrystalline, with layered crystalline regions with lateral dimensions of $\sim 0.1-1 \mathrm{~nm}$ dispersed within a gel-like phase. ${ }^{45}$ However, challenges remain in experimentally determining the detailed structure of this phase, in large part because this structure depends strongly on water content.

The correlation of composition and structure within the $\mathrm{C}-\mathrm{S}-\mathrm{H}$ phase thus remains an open issue. Several models have been proposed over the years ${ }^{46}$ to resolve apparently contradictory constraints, typically creating defects within crystalline mineral analogues to increase the calcium content while increasing the density. Although all such models can be adjusted to reproduce the experimentally measured $\mathrm{C} / \mathrm{S}$ ratio, it has remained challenging to simultaneously satisfy the constraints of the known water content and phase density. Additionally, such models describe purely crystalline structures that are not consistent with scattering and TEM data at the nanometer scale and the presence of a gel phase gluing layered crystallites. ${ }^{17} \mathrm{We}$ recently developed a structural description of C-S-H, based on Monte Carlo simulations, incorporating water molecules within a highly defective mineral structure that gives a $\mathrm{C} / \mathrm{S}$ ratio of about 1.7 and also a reasonable density of $\sim 2.4-2.5 \mathrm{~g} / \mathrm{cm}^{3}$. In this model, C-S-H has a defective structure with only shortrange order among silicate-rich layers, as distinguished from the original tobermorite mineral-based model of Pellenq and Van Damme that exhibited long-range order. ${ }^{47}$

A consistent structural description of C-S-H is desirable. Beyond addressing the longstanding composition/density puzzle at the nanoscale and the gel-versus-nanogranular interpretation of organization at the microscale, there are obvious consequences for concrete sustainability. For example, knowing the cement-paste stiffness or strength at the nano- and microscales, relative to cement chemistry in terms of the $\mathrm{C} / \mathrm{S}$ ratio, provides a direct path toward engineering a stiffer or stronger C-S-H phase. For structural applications such as pavements and buildings, this engineering of cement-paste mechanical properties can result in a reduced volume of C-S-H required and, thus, a lower associated carbon footprint of the embodied energy within such structures. Interestingly, a recent life-cycle assessment indicated that the embodied energy of buildings in the United States amounts to only a few percent of the use-stage energy (heating and cooling over the building lifetime), whereas this ratio can approach unity in Europe. ${ }^{48}$ The relevant material property here is thermal conductivity, and an open fundamental question is the relevant scale (if any) at which thermal transport properties of cement paste within concrete can be engineered to impact operational energy.

To refine multiscale C-S-H computational models and to test hypotheses for lowered $\mathrm{CO}_{2}$ contributions and increased sustainability of cement paste and concrete, experimental validation is required. Fortunately, C-S-H within hardened cement paste is accessible to nanoscale, microscale, and mesoscale analysis by both simulation and experiment (Figure 6). Characterization methods that are common to engineering materials, including instrumented indentation, scratch testing, electron microscopy, wavelength-dispersive $\mathrm{x}$-ray diffraction spectroscopy (WDS), and solid-state nuclear magnetic resonance (NMR) spectroscopy, are now being used to quantify how the mechanical, chemical, and structural properties depend on the chemical and physical environments of these pastes. In Figure 6, we show instrumentation and results for WDS analysis of chemical composition (Figure 6a); nanoindentation analysis of phase stiffness and strength (Figure 6b); and scratch-based estimation of fracture toughness (Figure 6c), along with typical results for a portland cement paste. Importantly, these and other chemical and mechanical properties (e.g., creep, shrinkage), as well as thermal properties (e.g., heat capacity ${ }^{49}$ and conductivity), can be measured for C-S-H and other phases within cement pastes and concrete over similar length scales and correlated with simulation predictions across length scales.

Further, water and electrolyte play a crucial role in the evolution and aging of the cement paste. This is particularly relevant at the level of C-S-H, where classical molecular simulations indicate that water is confined in nanopores. ${ }^{17}$ This nanopore region is hydrophilic because the nonbridging oxygen atoms on the disordered silicate chains act as hydrogen-bond-acceptor sites, orienting the hydrogen atoms of the interfacial water molecules toward the calcium silicate layers. Furthermore, the volume and mechanical properties of C-S-H vary strongly with ambient humidity ${ }^{50}$ and shrinkage is governed by water-filled pores at multiple length scales.

Exploration of silicate chain lengths as a function of water content is underway, comparing advanced techniques such as solid-state ${ }^{29} \mathrm{Si}$ NMR spectroscopy (Figure 6d), which indicates the extent of silicate linkages and chain length, with molecular simulations of C-S-H..$^{50}$ Nanopore water dynamics (reported as relaxation times) are also accessible with ${ }^{1} \mathrm{H}$ nuclear spin relaxation NMR spectroscopy. ${ }^{51}$ Bridging this microscale-macroscale gap has direct implications for concrete durability, as the motion of water among pores relates directly to the cohesion of the binding phase as a function of humidity and temperature and the physical state of water within pores affects durability under extreme changes in humidity, temperature, and mechanical strain. Here, predictable shrinkage and durability of the cement paste within concrete has an immediate impact on sustainability, for example, 

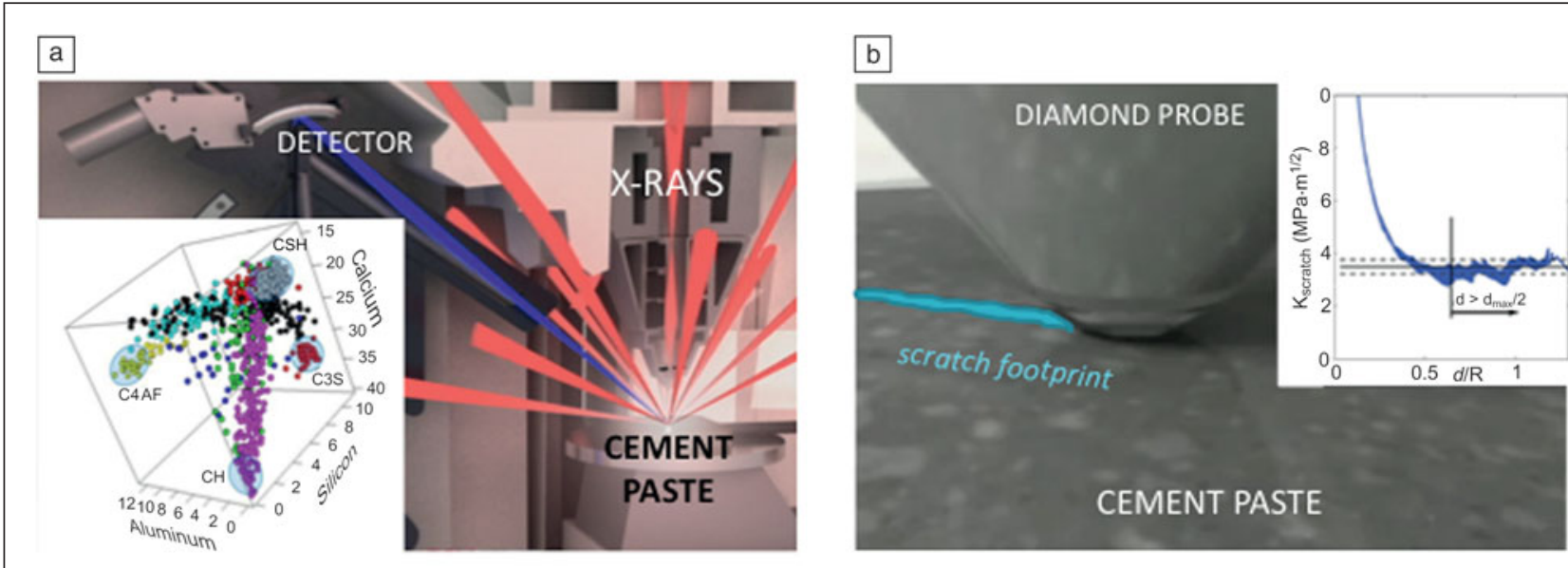

c

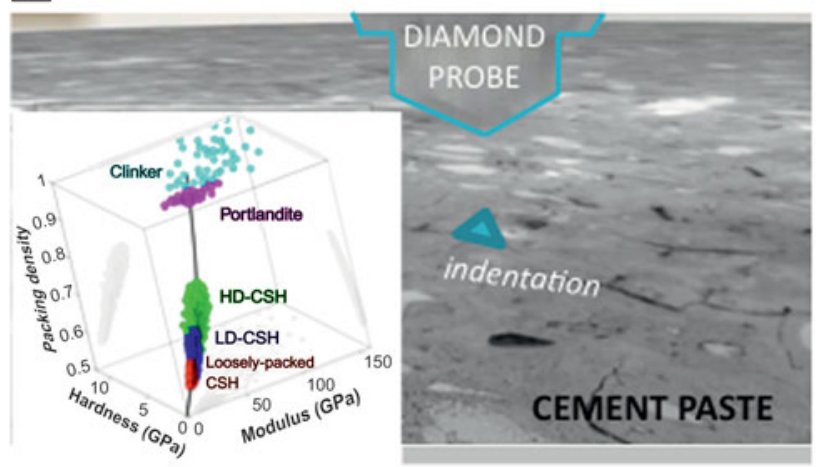

d

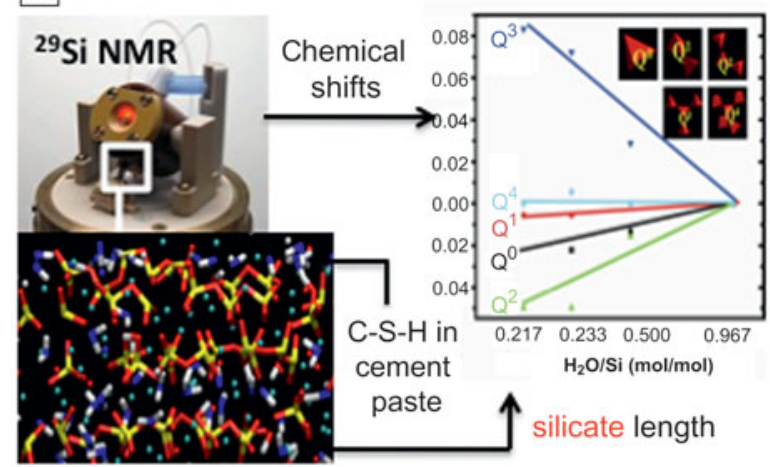

Figure 6. Experimental probes that can be used to characterize cement paste at small length scales. (a) Wavelength-dispersive x-ray diffraction spectroscopy (WDS) to infer chemistry, in a three-dimensional representation: portlandite (CH), calcium silicate hydrate (C-S-H), alite (C3S), and tetracalcium aluminoferrite (C4AF). (b) Scratch experiment with estimated fracture toughness as a function of the probe and scratch dimensions. (c) Nanoindentation experiment that can distinguish different components. The inset shows a three-dimensional plot of packing fraction, modulus, and hardness for typical regions consisting of the main components of a cement paste: portlandite, unreacted clinker, and loosely packed low- and high-density C-S-H (LD-CSH and HD-CSH, respectively). (d) Solid-state nuclear magnetic resonance (NMR) spectroscopy can measure silicate chain length in terms of $Q^{\prime}$, where $i$ denotes the number of bridging oxygens in the silicate, and the resulting data can be compared with atomistic simulations of $\mathrm{C}-\mathrm{S}-\mathrm{H}$ as a function of water content. ${ }^{49,50}$

as relates to decreased replacement demands for new raw materials in pavements and buildings and to improved performance in extreme weather, heating rates, or loading environments that currently cause warping, cracking, or phase changes.

\section{A view of mechanism-based concrete sustainability}

An increasing reliance on a mechanism-based approach to concrete sustainability reflects the general belief that more fundamental understanding of a phenomenon can translate into ways to reduce its impact. Thus, insights into clinker grinding and dissolution, C-S-H precipitation and setting, and the structure and durability of hardened paste could contribute to the development of alternative processing routes. For example, these insights could enable cement production at lower kiln temperatures and/or lower grinding energies, both of which would lower associated $\mathrm{CO}_{2}$ production. Additionally, correlation of C-S-H structure and multiscale mechanical and thermal properties will allow tailoring of such properties to infrastructure applications, potentially resulting in lowered demand for raw materials (and associated $\mathrm{CO}_{2}$ production). We have indicated a number of current examples of focused research that serve only as illustrations of the vast research opportunities available to the materials community. Indeed, one important trend in improving concrete sustainability is partial replacement of cement paste with recycled materials such as fly ash or fumed silica. However, the effects of such incorporation on reaction kinetics and achievable strength of such mixes add further complexity that can be addressed best by predictive understanding of cement paste. It should be clear that a decisive impact cannot be achieved without the active collaboration of industry, the end users of concrete science and technology who will make, modify, and innovate new applications for this amazing material called "liquid stone" that holds the world together.

\section{Acknowledgments}

We acknowledge the Concrete Sustainability Hub at Massachusetts Institute of Technology, supported by the Portland 
Cement Association and the National Ready Mix Concrete Association. K.J.V.V. also acknowledges the U.S. Department of Homeland Security, Science and Technology Directorate, Infrastructure Protection and Disaster Management Division and Engineer Research and Development Center (ERDC), U.S. Army Corps of Engineers.

\section{References}

1. S. Staniford, "A Pretty Stunning Graph of World Cement Production" (Institute for the Study of Energy and Our Future, Fort Collins, C0), oildrum.com/node/ 4162 (accessed March 2012).

2. H.G. van Oss, in Mineral Commodity Summaries 2006 (U.S. Geological Survey, Reston, VA, 2006), pp. 44-45.

3. H.G. van Oss, in Mineral Commodity Summaries 2008 (U.S. Geological Survey, Reston, VA, 2008), pp. 44-45.

4. Global Cement Report (International Cement Review, London, ed. 9, 2011).

5. J.E.A. Ochsendorf, L.K. Norford, D. Brown, H. Durschlag, S.L. Hsu, A. Love,

N. Santero, O. Swei, A. Webb, M. Wildnauer, Methods, Impacts, and Opportunities in the Concrete Building Life Cycle (Research Report R11-01, Massachusetts Institute of Technology, Cambridge, MA, 2011).

6. S. Yip, Ed., Handbook of Materials Modeling (Springer, New York, 2005).

7. J. Stark, Cem. Concr. Res. 41, 666 (2011).

8. J.J. Thomas, J.J. Biernacki, J.W. Bullard, S. Bishnoi, J.S. Dolado, G.W. Scherer, A. Luttge, Cem. Concr. Res. 41, 1257 (2011)

9. S. Bishnoi, K. Scrivener, Cem. Concr. Res. 39, 266 (2009).

10. H.F. Taylor, Cement Chemistry (Thomas Telford, London, ed. 2, 1997).

11. F.J. Ulm, A.T. Akono, P.M. Reis, Phys. Rev. Lett. 106, 204302 (2011).

12. A.K. Chatterjee, Cem. Concr. Res. 26, 1213 (1996).

13. C.D. Popescu, M. Muntean, J.H. Sharp, Cem. Concr. Compos. 25, 689 (2003).

14. E.M. Gartner, D.E. Macphee, Cem. Concr. Res. 41, 736 (2011).

15. A.J. Allen, J.J. Thomas, H.M. Jennings, Nat. Mater. 6, 311 (2007).

16. L.B. Skinner, S.R. Chae, C.J. Benmore, P. Monteiro, Phys. Rev. Lett. 104, $195502(2010)$.

17. R.J.-M. Pellenq, A. Kushima, R. Shahsavari, K.J. Van Vliet, M.J. Buehler, S. Yip, F.J. Ulm, Proc. Natl. Acad. Sci. U.S.A. 106, 16102 (2009).

18. B. Yildiz, M. Youssef, R.J.-M. Pellenq, J. Am. Chem. Soc. 133, 2499 (2011). 19. M. Vandamme, F.-J. Ulm, Proc. Natl. Acad. Sci. U.S.A. 106, 10552 (2009). 20. H. Manzano, J.S. Dolado, A. Ayuelaz, J. Am. Ceram. Soc. 92, 897 (2009).

21. T.T. Tran, D. Herfort, H.J. Jakobsen, J. Skibsted, J. Am. Chem. Soc. 131 14170 (2009).

22. A. Rawal, B.J. Smith, G.L. Athens, C.L. Edwards, L. Roberts, V. Gupta, B.F. Chmelka, J. Am. Chem. Soc. 132, 7321 (2010).

23. D. Stephan, S. Wistuba, J. Eur. Ceram. Soc. 26, 141 (2006)

24. Y.M. Kim, S.H. Hong, J. Am. Ceram. Soc. 87, 900 (2004).

25. A.J.M. Cuberos, A.G. De la Torre, G. Alvarez-Pinazo, M.C. Martin-Sedeno, K. Schollbach, H. Pollmann, M.A.G. Aranda, Environ. Sci. Technol. 44 (17), 6855 (2010).
26. M.C. Martin-Sedeno, A.J.M. Cuberos, A.G. De la Torre, G. Alvarez-Pinazo, L.M. Ordonez, M. Gateshki, M.A.G. Aranda, Cem. Concr. Res. 40 (3), 359 (2010) 27. A.G. De la Torre, K. Morsli, M. Zahir, M.A.G. Aranda, J. Appl. Crystallogr. 40, 999 (2007)

28. G.S. Li, G.M. Gartner, "High-Belite Sulfoaluminate Clinker: Fabrication Process and Binder Preparation," French Patent Application 04-51586 (27 January 2006). 29. E. Durgun, H. Manzano, R.J.-M. Pellenq, J.C. Grossman, "Understanding and Controlling the Reactivity of the Calcium Silicate Phases from First Principles," Chem. Mater., in press.

30. E.M. Gartner, J.F. Young, D.A. Damidot, I. Jawed, in Structure and Performance of Cements, P. Barnes, J. Bensted, Eds. (Spon Press, London, ed. 2, 2002), pp. 57-103.

31. J.W. Bullard, H.J. Jennings, R.A. Livingston, A. Nonat, G.W. Scherer, J.S. Schweitzer, K.L. Scrivener, J.J. Thomas, Cem. Concr. Res. 41, 1208 (2011). 32. K.L. Scrivener, A. Nonat. Cem. Concr. Res. 41, 651 (2011).

33. D. Lootens, P. Hebraud, E. Lecolier, H. Van Damme, Oil Gas Sci. Technol. 59, 31 (2004).

34. K. van Breugel, Cem. Concr. Res. 25, 522 (1995).

35. E.J. Garboczi, D.P. Bentz, K.A. Snyder, N.S. Martys, P.E. Stutzman, C.F. Ferraris, J.W. Bullard, An Electronic Monograph: Modeling and Measuring the Structure and Properties of Cement-Based Materials (National Institute of Standards and Technology, Gaithersburg, MD, 2005), concrete.nist.gov/monograph (accessed February 2012).

36. J.W. Bullard, Modell. Simul. Mater. Sci. Eng. 15, 711 (2007).

37. A. Laio, F.L. Gervasio, Rep. Prog. Phys. 71, 126601 (2008).

38. A. Kushima, J. Eapen, J. Li, S. Yip, T. Zhu, Eur. Phys. J. B 82, 271-293 (2011).

39. P.R. Monasterio, Ph.D. thesis, Massachusetts Institute of Technology, Cambridge, MA (2010)

40. P.R. Monasterio, E. Masero, R. Pellenq, S. Yip, paper presented at the 13th International Congress on the Chemistry of Cement (ICCC), Madrid, Spain, 3-8 July 2011.

41. J.J. Thomas, H.M. Jennings, A.J. Allen, Adv. Cem. Based Mater. 7, 119 (1998). 42. G. Constantinides, F.-J. Ulm, J. Mech. Phys. Solids 55, 64 (2007).

43. S. Garrault-Gauffinet, Experimental investigation of calcium silicate hydrate (C-S-H) nucleation. J. Cryst. Growth 200, 565 (1999).

44. I.G. Richardson, Cem. Concr. Res. 29, 1131 (1999).

45. Z. Xu, D. Viehland, Phys. Rev. Lett. 77, 952 (1996)

46. I.G. Richardson, Cem. Concr. Res. 38, 137 (2007).

47. R.J.-M. Pellenq, H. Van Damme, MRS Bull. 29, 319 (2004).

48. Y.G. Yohanis, B. Norton, Energy 27, 77 (2002).

49. F. Vodak, R. Cerny, J. Drchalova, S. Hoskova, 0. Kapickova, O. Michalko, P. Semerak, J. Toman, Cem. Concr. Res. 27, 415 (1997).

50. Q. Ji, R.J.-M. Pellenq, K.J. Van Vliet, C-S-H: Water, water everywhere (Research Profile Letter, Concrete Sustainability Hub@MIT, Cambridge, MA, December 2010), web.mit.edu/cshub/news/pdf/12-2010\%20CSHub-NewsBrief\%20(1).pdf (accessed February 2012)

51. P.J. McDonald, J.-P. Korb, J. Mitchell, L. Monteilhet, Phys. Rev. E72, 011409 (2005).

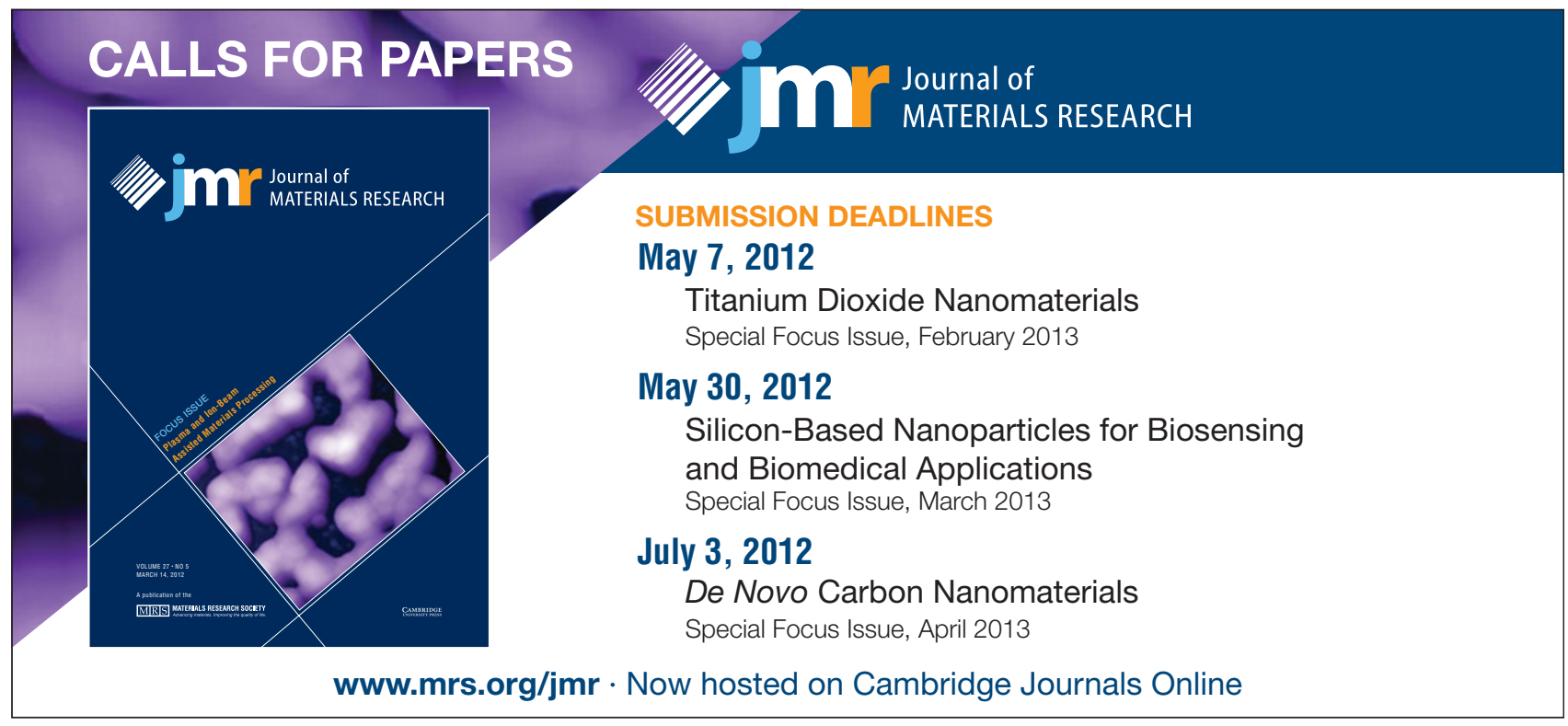




\section{The first truly global foundry}

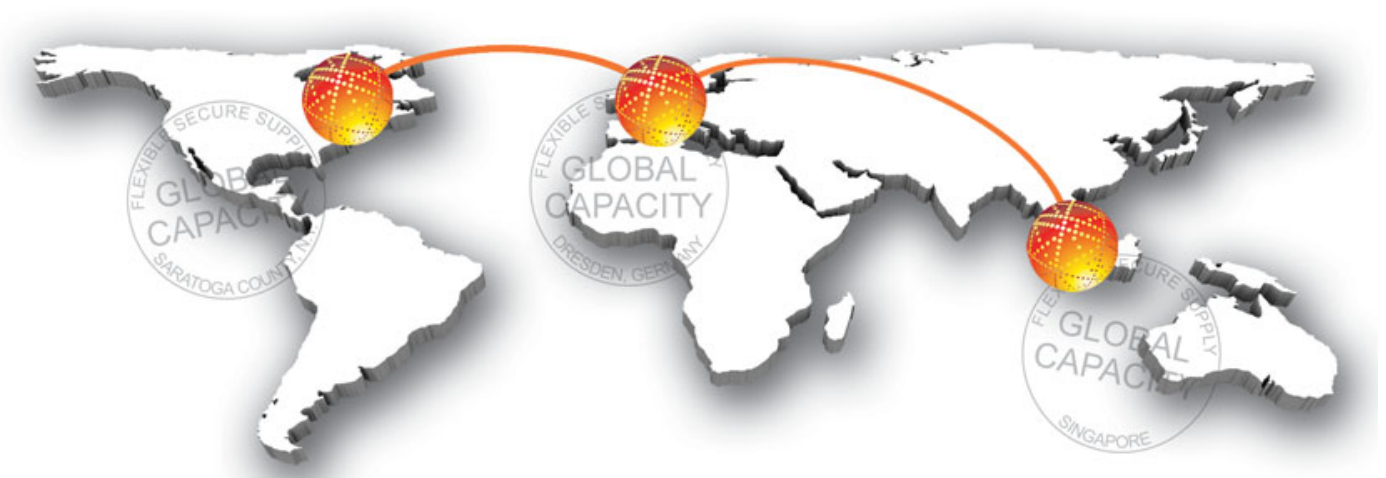

In January 2010, the semiconductor foundry landscape changed forever with the launch of the new GLOBALFOUNDRIES. This new entrant to the market combined the leading-edge integrated device manufacturing heritage of Advanced Micro Devices (AMD) with the pure-play semiconductor foundry heritage of Chartered Semiconductor to create a company with an impressive capacity and technology footprint and a world-class customer base.

Headquartered in Silicon Valley, our leading edge technology company has well over 10,000 employees with an extensive $200 \mathrm{~mm}$ and $300 \mathrm{~mm}$ silicon wafer manufacturing campus in Singapore. This is complemented by a leading-edge $300 \mathrm{~mm}$ manufacturing campus in Dresden, Germany and a third campus under construction in Saratoga County, New York, that once complete should be the most advanced in the world. These global operations provide a unique opportunity for us to attract and leverage the best engineering and technical talent from around the world to support long-term growth and expansion opportunities. 


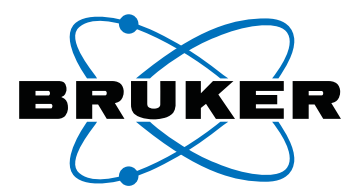

\section{The World's Fastest AFM}

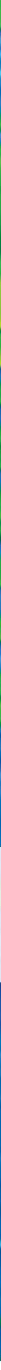

Imagine working 100s of times faster... and imagine doing it with an AFM that breaks the mold for speed and imaging performance. Well, there is no need to dream, Bruker's Dimension FastScan is the new gold standard in AFM technology. Dimension FastScan provides true fast scanning, on any sample, air or fluid, is easy to use and provides the world's highest AFM resolution and performance due to the system's lowest drift and low noise. Speed up your productivity and discover Dimension FastScan for yourself. View high-resolution FastScan images at our website, or experience it on your sample - call for a demonstration.

For more information visit www.bruker-axs.com, email productinfo@bruker-nano.com or call +1.805.967.1400 / 800.366.9956

Innovation with Integrity 